\title{
Hardness evaluation of prosthetic silicones containing opacifiers following chemical disinfection and accelerated aging
}

\author{
Marcelo Coelho Goiato ${ }^{(a)}$ \\ Marcela Filié Haddad(b) \\ Daniela Micheline dos Santos ${ }^{(a)}$ \\ Aldiéris Alves Pesqueira ${ }^{(b)}$ \\ Amália Moreno(b)
}

(a) Associate Professor; (b) Graduate Student - Department of Dental Materials and Prosthodontics, Araçatuba Dental School, São Paulo State University (UNESP), Araçatuba, São Paulo, Brazil.

\section{Corresponding author:}

Marcelo Coelho Goiato

Faculdade de Odontologia de Araçatuba - UNESP

Departamento de Materiais Odontológicos e Prótese

Rua José Bonifácio, 11 193, Vila Mendonça Araçatuba - SP - Brazil

E-mail: goiato@foa.unesp.br

Received for publication on Apr 29, 2010 Accepted for publication on Jun 06, 2010

\begin{abstract}
We evaluated the effects of disinfection and aging on the hardness of silicones containing opacifiers and intended for use in facial prosthetics. A total of 90 samples were produced using a cylindrical metal mold $3 \mathrm{~mm}$ in height and $30 \mathrm{~mm}$ in diameter. The samples were fabricated from Silastic MDX 4-4210 silicone in three groups: GI contained no opacifier, GII contained barium sulfate (Ba), and GIII contained titanium dioxide (Ti). The samples were disinfected using effervescent tablets (Ef), neutral soap (Ns), or $4 \%$ chlorhexidine $(\mathrm{Cl}) 3$ times a week for 60 days. After this period the samples underwent 1,008 hours of accelerated aging. The hardness was measured using a durometer immediately following the disinfection period and after 252, 504, and 1,008 hours of aging. The data were statistically analyzed using 3-way ANOVA and the Tukey test $(p<.05)$. The GIII group exhibited the greatest variation in hardness regardless of elapsed time. All groups displayed greater hardness after 1,008 hours of accelerated aging independent of disinfectant type. All of the hardness values were within the clinically acceptable range.
\end{abstract}

Descriptors: Maxillofacial prosthesis; Disinfection; Hardness.

\section{Introduction}

Deformities in the maxillofacial area can cause embarrassment for patients. ${ }^{1}$ Plastic surgery is the first choice of treatment, but when surgery is inadvisable due to unfavorable conditions, rehabilitation with maxillofacial prostheses provides a means of improving patient aesthetics and self-esteem and facilitating their return to society. ${ }^{1,2}$

Silicone is the most common material used to fabricate maxillofacial prostheses because of its texture, strength, durability, ease in handling and coloring, and patient comfort. ${ }^{2,3}$ However, silicone suffers from a rapid deterioration of physical properties and color instability and is difficult to repair, limiting its use in maxillofacial prostheses. After a few months of insertion, the prosthesis becomes unpleasant, ${ }^{4-6}$ and microorganisms colonizing the silicone $e^{7,8}$ may promote infection of surrounding tissues. ${ }^{1,2}$

A recent method of silicone pigmentation involves adding opacifiers to the base material. ${ }^{9-10}$ This method reduces color instability ${ }^{11-13}$ by blocking ultraviolet rays. ${ }^{9-10}$ However, changes to the physical properties 
(such as hardness) resulting from addition of these materials have not been investigated. We examined the effects of barium sulfate and titanium dioxide opacifiers on the hardness of Silastic MDX4-4210 following chemical disinfection and accelerated aging. Our hypothesis was that the opacifiers did not affect the physical properties of the silicone.

\section{Material and Methods}

The samples were fabricated by filling $30 \mathrm{~mm}$ diameter x $3 \mathrm{~mm}$ thick cylindrical metal molds ${ }^{6}$ with Silastic MDX4-4210 (Dow Corning Corporation, Midland, MI, USA). Barium sulfate (Wako, Osaka, Osaka, Japan) or titanium dioxide (Homeofar, Catanduva, SP, Brazil) were added to some of the samples as opacifiers. A total of 90 samples were fabricated in three groups $(n=30)$ : the GI group contained no opacifier, the GII group was pigmented with $0.2 \mathrm{wt} \%$ barium sulfate $(\mathrm{Ba})$, and the GIII group was pigmented with $0.2 \mathrm{wt} \%$ titanium dioxide (Ti). Both the pigments and the silicones were weighed using a precision digital scale (BEL Equipamentos Analítico, Piracicaba, SP, Brazil). ${ }^{4,14,15}$ The silicone was mixed according to the manufacturer's instructions. The opacifiers were mixed with the silicone and the mixture was placed in the mold. Excess material was removed to maintain a uniform thickness. The samples were cured in the molds for 3 days with the external surface left exposed. $2,6,14,16$

After curing, an initial Shore A hardness test was performed on all samples using a digital durometer (Teclock, Osaka, Osaka, Japan) according to ASTM procedures. ${ }^{17}$ The potency of the measurement was established between 0 and 100 Shore A, with $\pm 1 \%$ of tolerance. The sample loading was $12.5 \mathrm{~N}$ for 10 seconds. Shore A hardness is a measure of material texture and flexibility and should be between 25 and 35 units for maxillofacial prosthetic materials. ${ }^{2,18-19}$

The samples were disinfected 3 times a week for 60 days. ${ }^{6,16,20-21}$ Within each group, 10 samples were disinfected with Efferdent (Ef - Pfizer Consumer Health, Morris Plains, NJ, USA), ${ }^{6,20} 10$ with neutral pH soap (Ns - Johnson \& Johnson, São José dos Campos, SP, Brazil), ${ }^{6,20}$ and ten with $4 \%$ gluconate chlorhexidine (Cl - Naturativa, Araçatuba, SP, Brazil). ${ }^{2,21,22}$ After disinfection, the samples were again tested for hardness.

Accelerated aging tests were carried out using an aging chamber (Equilam, Diadema, SP, Brazil). ${ }^{6}$ The samples were subjected to alternating periods of exposure to ultraviolet light and distilled water. ${ }^{4,14}$ Hardness tests were repeated after 252, 504, and 1,008 hours of aging. ${ }^{8}$

The hardness values were analyzed using 3-way ANOVA and the means were compared using the Tukey test $(p<.05)$.

\section{Results}

The mean hardness values are presented in Tables 1 and 2 and Graphs 1-3.

The opacifier, disinfection, and aging treatments were statistically significant with respect to hardness $(\mathrm{p}<.05)$. The GI and GII groups increased in hardness throughout the experiment. On the other

Table 1 - ANOVA results for hardness tests.

\begin{tabular}{c|r|r|r|r|r}
\hline Source & \multicolumn{1}{c|}{ df } & \multicolumn{1}{c|}{ SS } & \multicolumn{1}{c|}{ MS } & \multicolumn{1}{c}{$F$} & \multicolumn{1}{c}{$P$} \\
\hline Disinfectant & 2 & 9.204 & 4.602 & 3.870 & \multicolumn{1}{c}{$.025^{*}$} \\
\hline Opacifier & 2 & 129.391 & 64.696 & 54.406 & $<.0001^{*}$ \\
\hline Disinf X Opac & 4 & 17.582 & 4.396 & 3.696 & $.008^{*}$ \\
\hline Between subjects & 81 & 96.320 & 1.189 & & \\
\hline Aging & 4 & 900.476 & 225.119 & 442.911 & $<.0001^{*}$ \\
\hline Aging X Disinf & 8 & 56.484 & 7.061 & 13.891 & $<.0001^{*}$ \\
\hline Aging X Opac & 8 & 320.831 & 40.104 & 78.902 & $<.0001^{*}$ \\
\hline Aging X Disinf X Opac & 16 & 69.929 & 4.371 & 8.599 & $<.0001^{*}$ \\
\hline Within subjects & 324 & 164.680 & 0.508 & & \\
\hline
\end{tabular}

${ }^{*} p<.05$ denotes statistically significant difference. $d f$ : degrees of freedom, SS: sum of squares, MS: mean square. 
Table 2 - Mean hardness values (SD) for Silastic silicones between chemical disinfectant groups.

\begin{tabular}{|c|c|c|c|c|}
\hline \multirow{2}{*}{ Period } & \multirow{2}{*}{ Disinfec } & \multicolumn{3}{|c|}{ Groups } \\
\hline & & $\mathrm{Gl}$ & G॥ & GIII \\
\hline \multirow{3}{*}{ Initial } & Ef & $28.7(0.82) \mathrm{ABa}$ & $28.6(0.52) \mathrm{ABCa}$ & $29.6(0.7) \quad A B C a$ \\
\hline & Ns & $28.2(0.79) \mathrm{Aa}$ & $28.2(0.79) \mathrm{Aa}$ & $29.3(0.48) \mathrm{ABCa}$ \\
\hline & $\mathrm{Cl}$ & $29 \quad(0.47) \mathrm{ABCa}$ & $28.5(0.53) \mathrm{Aa}$ & $29.2(0.63) \mathrm{ABa}$ \\
\hline \multirow{3}{*}{60 days } & Ef & $29.8(0.42) \mathrm{BCDa}$ & $28.7(0.7) \quad \mathrm{Aa}$ & $28.7(0.48) \mathrm{ADa}$ \\
\hline & Ns & $30.4(0.52) \mathrm{CDEFa}$ & $30.7(1.16) \mathrm{CDEa}$ & $28.7(0.95)$ ADb \\
\hline & $\mathrm{Cl}$ & 30.1 (0.57) BCDEa & $29.1(0.57) \mathrm{ABa}$ & $27.6(0.52) \mathrm{CDEb}$ \\
\hline \multirow{3}{*}{$\begin{array}{c}252 \\
\text { hours }\end{array}$} & Ef & $30.3(0.95) \mathrm{CDEFa}$ & $29.3(1.16) \mathrm{ABa}$ & $27.4(0.52) \mathrm{DEb}$ \\
\hline & Ns & 30.7 (0.95) DEFa & $31.3(1.06)$ DEFGa & 27.5 (0.71) DEb \\
\hline & $\mathrm{Cl}$ & $30.4(1.17) \mathrm{CDEFa}$ & $30.6(0.97) \mathrm{CDEa}$ & $30.3(0.7) \quad \mathrm{Ba}$ \\
\hline \multirow{3}{*}{$\begin{array}{l}504 \\
\text { hours }\end{array}$} & Ef & 30.9 (0.88) EFGa & $30.2(0.92) \mathrm{BCDa}$ & $27.4(0.7) \quad$ DEb \\
\hline & Ns & 31.7 (0.95) FGHla & $31.7(1.16)$ EFGa & $27 \quad(0.47) \mathrm{Eb}$ \\
\hline & $\mathrm{Cl}$ & 31.5 (1.08) EFGHa & 30.8 (1.03) CDEFa & $27.6(0.95) \mathrm{DEb}$ \\
\hline \multirow{3}{*}{$\begin{array}{l}1,008 \\
\text { hours }\end{array}$} & Ef & $33 \quad(0.82)$ la & $32.7(0.82) \mathrm{Ga}$ & $33.1(0.74) \mathrm{Fa}$ \\
\hline & Ns & $32.4(0.84) \mathrm{Hla}$ & $32.4(0.7) \quad \mathrm{Ga}$ & $33.5(0.71) \mathrm{Fa}$ \\
\hline & $\mathrm{Cl}$ & $32.2(0.92) \mathrm{GHla}$ & $32.7(0.67) \mathrm{Ga}$ & $34(0.67) \quad \mathrm{Fa}$ \\
\hline
\end{tabular}

Means followed by the same capital letter in column and same lowercase letter in line exhibit no statistical difference $(\mathrm{p}<0.05)$ by Tukey test. Ef: Efferdent, Ns: neutral pH soap, $\mathrm{Cl}$ : chlorhexidine.

hand, GIII exhibited a significant decrease in hardness following disinfection and after 252 hours of accelerated aging (Graphs 1-3), except for samples disinfected with chlorhexidine. After 1,008 hours of aging, the hardness of the GIII samples increased independent of the disinfectant used (Graphs 1-3).

After 60 days of Ef disinfection, the GII and GIII samples exhibited lower hardness values than the GI group (Table 2). The hardness values of the GIII samples were lower than the GI and GII samples after 252 and 504 hours of aging regardless of disinfection procedure (Table 2). However, the GIII samples had the highest hardness after 1,008 hours (Table 2).

Chemical disinfection and accelerated aging did not statistically influence the mean hardness of the GI group, but when an opacifier was added both disinfection and accelerated aging produced significant changes in hardness (Table 2).

\section{Discussion}

All values obtained in the present study were within the acceptable range described in the literature (25-35 units) $)^{2,6,18,23}$ regardless of opacifier ad- dition, disinfection, or aging (table 2). However, the hypothesis of the present study was rejected because when an opacifier was added both disinfection and accelerated aging produced significant changes in silicone hardness (Table 2).

In the present study, an increase in hardness was observed in the GI and GII groups both after disinfection and accelerated aging. The increases were only statistically significant after disinfection with neutral soup and accelerated aging (Graphs 1-3 and table 2), and could be the result of ongoing silicone polymerization with volatilization of formaldehyde,${ }^{24}$ which occurs during the aging process. The cross-linking system used in this material produces high temperatures, increasing the conversion rate, cross-linking density, and molecular weight of the silicone polymer ${ }^{6,25}$ to improve the hardness of the material.

It is likely that $\mathrm{Ba}$ does not alter the silicone matrix since the behavior exhibited by Ba-containing samples was similar to the unmodified samples. In addition, Ba particles are capable of strongly associating with silicone chains even after disinfection. If the barium sulfate particles were removed during 


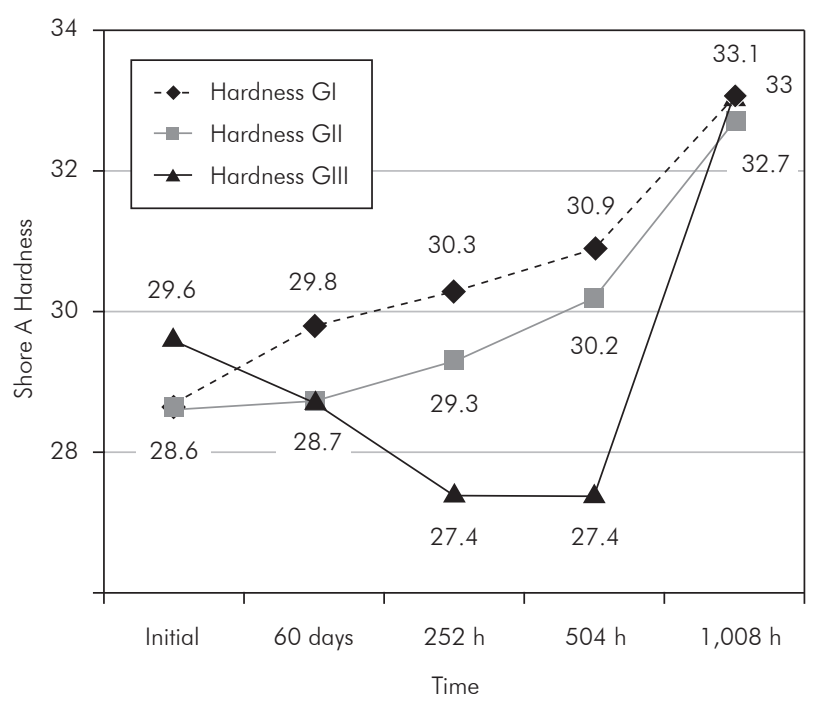

Graph 1 - Mean hardness values of Silastic disinfected with Efferdent.

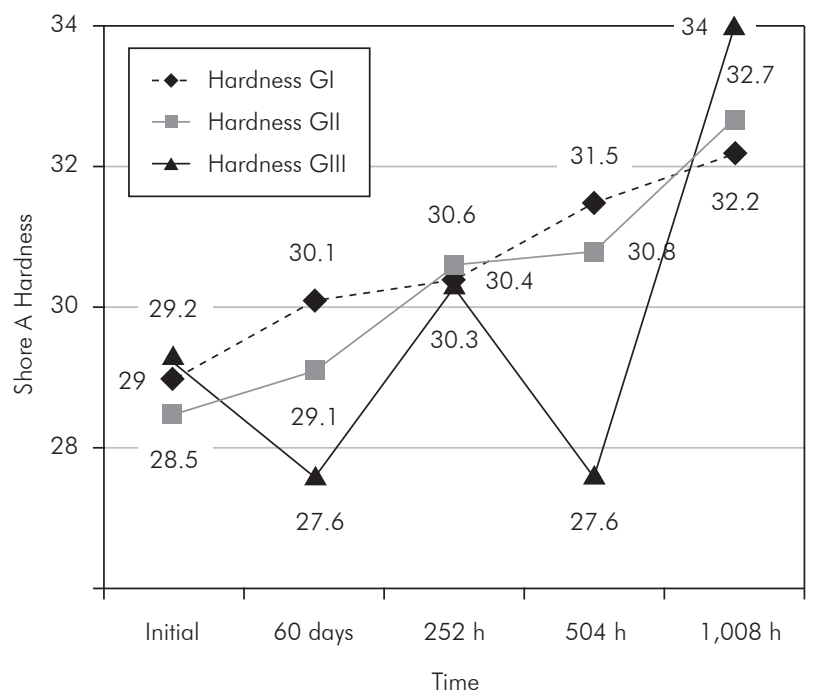

Graph 3 - Mean hardness values of Silastic disinfected with chlorhexidine.

disinfection, an increase in porosity and reduced hardness would be expected. ${ }^{6}$

The GIII group displayed a decrease in hardness after 252 hours of accelerated aging, except for samples disinfected with chlorhexidine, and a significant increase in hardness after 1008 hours, regardless of the disinfection procedure.

After 60 days of disinfection with Ef, the GII and GIII groups exhibited lower hardness values than the GI group (Graph 1, table 2). The hardness

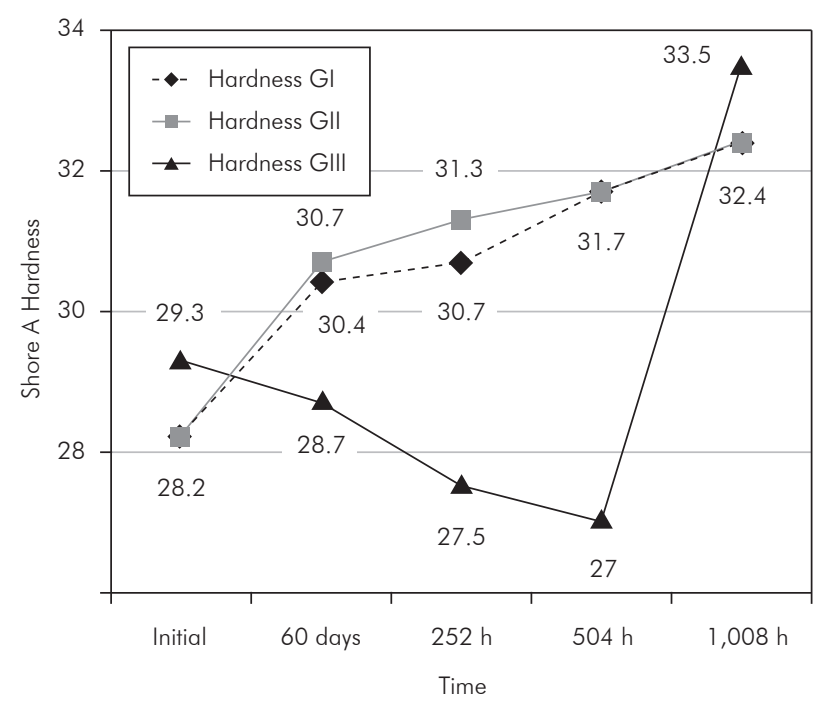

Graph 2 - Mean hardness values of Silastic disinfected with neutral soap.

values of the GIII samples were also lower than the GI and GII groups after 252 and 504 hours of accelerated aging independent of the disinfection procedure (Graphs 1-3, Table 2).

Both the high hardness values in the initial period and the low hardness values after disinfection and accelerated aging (252 and 504 hours) are probably due to continuous polymerization of the silicone. ${ }^{4,6,19}$

The polymerization process can be slowed by reaction between the disinfection products and the titanium dioxide opacifier. If the titanium dioxide particles are smaller than the barium sulfate particles, a portion of the titanium opacifier could have been removed during disinfection, resulting in more porous and softer samples. ${ }^{6,19}$

One reason for the significantly lower hardness value observed in the GIII group after chlorhexidine treatment (Graph 3, Table 2) is absorption of the disinfection solution. The samples were immersed in $\mathrm{Cl}$ during the disinfection procedure, so a porous structure may have been formed. Mancuso et al. ${ }^{19}$ stated that additives to silicone materials may promote water absorption and lead to reduced hardness.

After 1,008 hours of accelerated aging, the hardness values of the GIII group were higher than those of the other groups (Table 2), suggesting that at the 
end of the aging period the material reached a higher degree of polymerization for all samples. ${ }^{6,19}$

Although hygiene is important in maxillofacial prostheses, there is no universally effective method for performing this maintenance. Brushing is not advisable because repeated washing may dissolve and remove some surface pigments. Rinsing with tap water is ineffective against calculus buildup and stains. ${ }^{6}$ Chemical soaking is the primary method of choice to disinfect maxillofacial elastomers. Patients are advised not to clean the prosthesis using solvents, such as isopropyl alcohol since this could cause dissolution of the pigments. The methods used in the present study included Efferdent tablets that employ saturation and oxidation using peroxides, neutral soap that acts through digital friction and is chemically inert ${ }^{6}$ and $4 \%$ chlorhexidine, also chemically inert and acting through saturation. ${ }^{22}$

None of the disinfectants used in the present study statistically affected the hardness value of the MDX4-4210 silicone, but when an opacifier was added, both the disinfection method and the aging process produced statistically significant changes in the material hardness. Only the GII samples disinfected with neutral soap experienced a significant increase in hardness. This result reinforces our previous supposition that the opacifier forms a strong link with the silicone chains, and this association is not broken even with digital friction during the disinfection procedure. ${ }^{6}$ The lower hardness values observed in the GII and GIII groups disinfected with
$\mathrm{Cl}$ (Table 2) can be explained by the disinfection method (immersion). According to the literature, long-term storage of silicone materials can promote water absorption, and the degree of absorption is dependent on the filler material (opacifiers) and the low level of adhesion between silicone polymers. ${ }^{26}$

This trend was not observed in the GII and GIII samples disinfected with Ef (Table 2), which also acts by immersion. Prostheses disinfected with Ef have a tendency to change color because of the alkaline peroxides in the Ef tablets, which oxidize organic materials when released in solution. This tends to make the silicone more porous and consequently reduces the hardness. ${ }^{20}$ Since the opacifiers used in this study were inorganic, the oxygen discoloration did not occur and the initial hardness was maintained.

According to the results of the present study, hardness values did not significantly differ with regard to disinfection process (Table 2), and all hardness values were within the acceptable clinical range (25 to 35 units). ${ }^{2,6,18-19}$ The samples were subjected to 1,008 hours of accelerated aging, equivalent to 1 year of clinical use. ${ }^{14}$

\section{Conclusion}

Within the limitations of this in vitro study, it can be concluded that the use of opacifiers and disinfection procedures in Silastic silicone prostheses is acceptable.

\section{References}

1. Goiato MC, Pesqueira AA, Ramos da Silva C, Gennari-Filho $\mathrm{H}$, Micheline dos Santos D. Patient satisfaction with maxillofacial prosthesis: literature review. J Plast Reconstr Aesthet Surg. 2009 Feb;62(2):175-80.

2. Guiotti AM, Goiato MC, dos Santos DM. Evaluation of the Shore A hardness a silicone for facial prosthesis as to the effect of storage period and chemical disinfection. J Craniofac Surg. 2010 Mar;21(2):323-7.

3. Dootz ER, Koran A 3rd, Craig RG. Physical properties of three maxillofacial materials as a function of accelerated aging. J Prosthet Dent. 1994 Apr;71(4):379-83.

4. Mancuso DN, Goiato MC, Santos DM. Color stability after accelerated aging of two silicones, pigmented or not, for use

in facial prostheses. Braz Oral Res. 2009 Apr-Jun;23(2):1448.

5. Aziz T, Waters M, Jagger R. Development of a new poly(dimethylsiloxane) maxillofacial prosthetic material. J Biomed Mater Res B Appl Biomater. 2003 May;65(2):25261.

6. Goiato MC, Pesqueira AA, dos Santos DM, Dekon SF. Evaluation of hardness and surface roughness of two maxillofacial silicones following disinfection. Braz Oral Res. 2009 JanMar;23(1):49-53.

7. Nikawa H, Jin C, Hamada T, Makihira S, Polyzois G. Candida albicans growth on thermal cycled materials for maxillofacial prosthesis in vitro. J Oral Rehabil. 2001 Aug;28(8):755-65. 
8. Taylor RL, Liauw CM, Maryan C. The effect of resin/crosslinker ratio on the mechanical properties and fungal deterioration of a maxillofacial silicone elastomer. J Mater Sci Mater Med. 2003 Jun;14(6):497-502.

9. Gasparro FP, Mitchnick M, Nash JF. A review of sunscreen safety an efficacy. Photochem Photobiol. 1998;68(3):24356.

10. Lowe NJ, Shaath MA, Pathak MA. Sunscreen development, evaluation and regulatory aspects, New York: Marcel Dekker; 1997

11. Kiat-amnuay S, Beerbower M, Powers J, Paravina RD. Influence of pigments and opacifiers on color stability of silicone maxillofacial elastomer. J Dent. 2009;37 Supplç 1:e45-50.

12. Santos DM, Goiato MC, Moreno A, Pesqueira AA, Haddad MF. Influence of pigments and opacifiers on color stability of a facial silicone submitted to accelerated aging. J Prosthodont. 2010 (In press).

13. Kiat-Amnuay S, Mekayarajjananonth T, Powers JM, Chambers MS, Lemon JC. Interactions of pigments and opacifiers on color stability of MDX4-4210/type A maxillofacial elastomers subjected to artificial aging. J Prosthet Dent. 2006 Mar;95(3):249-57.

14. Mancuso DN, Goiato MC, Dekon SFC, Gennari-Filho H. Visual evaluation of color stability after accelerated aging of pigmented and nonpigmented silicones to be used in facial prostheses. Indian J Dent Res. 2009 Jan-Mar;20(1):77-80.

15. Yu R, Koran 3rd, Craig RG. Physical properties of a pigmented silicone maxillofacial material as a function of accelerated aging. J Dent Res. 1980 Jul; 59(7):1141-8.

16. Goiato MC, Pesqueira AA, dos Santos DM, Falcón-Antenucci RM, Ribeiro PP. Evaluation of dimensional change and detail reproduction in silicones for facial prostheses. Acta Odontol Latinoam. 2008; 21(1):85-8.
17. American Society for Testing and Materials. Annual book of ASTM standards. Philadelphia: American Society for Testing and Materials; 1988. Designation D 2240-81: standard test method for rubber properties - Durometer hardness; 33235 .

18. Lewis DH, Castleberry DJ. An assessment of recent advances in external maxillofacial materials. J Prosthet Dent.1980 Apr;43(4):426-32.

19. Mancuso DN, Goiato MC, Zuccolotti BC, Moreno A, dos Santos DM. Evaluation of hardness and color change of soft liners after accelerated ageing. Prim Dent Care. 2009 Jul;16(3):12730.

20. Goiato MC, Pesqueira AA, dos Santos DM, Zavanelli AC, Ribeiro PP. Color stability comparison of silicone facial prostheses following disinfection. J Prosthodont. 2009 Apr;18(3):2424.

21. Goiato MC, Santos DM, Gennari Filho H, Zavanelli AC, Dekon SFC, Mancuso DN. Influence of investment, disinfection, and storage on the microhardness of ocular resins. J Prosthodont. 2009 Jan;18(1):32-5.

22. Pavarina AC, Pizzolitto AZ, Machado AL, Vergani CE, Giampaolo ET. An infection control protocol: effectiveness of immersion solutions to reduce the microbial growth on dental prostheses. J Oral Rehabil. 2003 May;30(5):532-6.

23. May PD. Maxillofacial prostheses of chlorinated polyethylene. J Biomed Mater Res.1978 May;12(3):421-31.

24. Anusavice K J. Phillips' Science of Dental Materials. $11^{\text {th }}$ ed. St Louis: Elsevier; 2003, 832 p.

25. Aziz T, Watersa M, Jagger R. Analysis of the properties of silicone rubber maxillofacial prosthetic materials. J Dent. 2003 Jan;31(1):67-74.

26. Qudah S, Hugget R, Harisan A. The effect of thermocycling on the hardness of soft lining materials. Quintessence Int. 1991 Jul;22(7):575-80. 